\title{
Circulating tumor DNA moves further into the spotlight
}

Mark Sausen ${ }^{1}$, Sonya Parpart ${ }^{1}$ and Luis A Diaz Jr $\mathrm{J}^{2,3^{*}}$

\begin{abstract}
Assessment of somatic genomic alterations from tumors can now be performed by sequencing circulating tumor DNA from the cell-free component of blood. This procedure, which identifies tumor-derived somatic mutations from a simple blood sample, circumvents the need for tumor tissue. A recent study highlights the promise of circulating tumor DNA to guide therapeutic decisions in a variety of solid tumors for both clinical and investigative purposes, as well as providing a tool for the early detection of cancer.
\end{abstract}

The presence of cell-free DNA in the circulation was first formally described by Mandel and Metais in 1948 [1]. Soon after, circulating tumor DNA (ctDNA) was noted to be the tumor-derived fraction in the cell-free DNA component of blood [2]. ctDNA can be detected across many common solid tumor types in patients in both early and late stages of cancer, with levels ranging from less than one to greater than 100,000 mutant DNA fragments per milliliter of plasma [3-5]. The utility of ctDNA as a cancer biomarker hinges on the exquisite specificity of somatic genomic alterations in patients with cancer. Unlike other tumor biomarkers, the specificity of somatic alterations is derived from the fact that mutations are present in the genome(s) of tumor cells but not in the genome of matched normal cells.

Many advances in this area have been possible through recent developments in digital genomic approaches (for example, digital PCR). These methods allow for the identification of somatic, or tumor-specific, mutations with allele fractions as low as $0.01 \%$ in a wild-type background

\footnotetext{
* Correspondence: Idiaz1@jhmi.edu

${ }^{2}$ Ludwig Center for Cancer Genetics and Therapeutics, Howard Hughes Medical Institute and the Sidney Kimmel Comprehensive Cancer Center at Johns Hopkins, Baltimore, MD 21287, USA

${ }^{3}$ Swim Across America Laboratory at Johns Hopkins, Baltimore, MD 21287, USA Full list of author information is available at the end of the article
}

[5]. Advances in digital genomics have opened the door for reliably evaluating very rare events in complex mixtures of tumor-derived and wild-type DNA. As a result, there has been a flurry of studies that detail the biology and clinical applicability of ctDNA [3,6,7].

One such recent study by Newman et al. [8] describes a novel cancer profiling method for non-small cell lung cancer (NSCLC) using deep sequencing (CAPP-Seq; cancer personalized profiling by deep sequencing) to quantify ctDNA. This approach allows the evaluation of specific regions of interest contained within ctDNA, and results in a significant cost reduction and improved sensitivity over whole-exome- and whole-genome-based approaches. A targeted 139 gene panel, or 'selector', for NSCLC was designed by analyzing whole-genome sequencing data for several types of somatic alterations, including sequence mutations and translocations, and was shown to detect $>95 \%$ of cases. When applied to plasma collected from five healthy controls and 13 patients with NSCLC, CAPP-Seq achieved a sensitivity of $85 \%$ and specificity of $96 \%$ for detection of ctDNA. A sensitivity of $50 \%$ was achieved for patients at stage I and $100 \%$ for those at stages II to IV, while specificity was $96 \%$ in both groups, similar to previous evaluations of patients with early- and late-stage disease [3].

Furthermore, until now, it has been difficult to evaluate mutational heterogeneity within and among tumors in a single patient because of the need for multiple tumor biopsies. Mutational heterogeneity can also be increased after therapy [6,7]. The less invasive nature of liquid biopsies, in addition to the comprehensive information they achieve, makes this form of biopsy ideal to monitor a patient's response to therapy and find additional mutations that may occur over time. The Newman et al. study highlights the utility of liquid biopsies for this purpose when examining two recurrently mutated genes, EGFR and KRAS. Their CAPP-Seq method correctly identified all mutations with allelic fractions $>0.10 \%$ and yielded a specificity of $99 \%$. Somatic mutations included two different EGFR mutations: an activating mutation in a dominant

C Biomed Central

(C) 2014 Sausen et al.; licensee BioMed Central Ltd. The licensee has exclusive rights to distribute this article, in any medium, for 12 months following its publication. After this time, the article is available under the terms of the Creative Commons Attribution License (http://creativecommons.org/licenses/by/4.0), which permits unrestricted use, distribution, and reproduction in any medium, provided the original work is properly credited. The Creative Commons Public Domain Dedication waiver (http://creativecommons.org/publicdomain/zero/1.0/) applies to the data made available in this article, unless otherwise stated. 
tumor clone as well as a second T790M mutation present in an erlotinib-resistant subclone. Of note, the mutations were identified in both the tumor tissue and ctDNA of this patient. Though evidence of multiple clones was found in only a single patient, this example demonstrates the ability of ctDNA to both address tumor heterogeneity and find clinically relevant mutations stemming from subclonal tumor populations.

The work presented by Newman and colleagues is yet another step forward as it advances the practicality of using ctDNA. However, the next phase of studies in the field of ctDNA will be critical to define the clinical value of this technology. What are the key next steps? First, we need to better understand biologic sensitivity; in other words, how much ctDNA is present in the circulation at each stage of disease and across disease types. Initial studies have begun to probe this question but, as larger clinical studies are contemplated, it is critical to understand both the variability in the amounts of ctDNA present and the etiology of this variability.

Second, we need to move beyond point mutations in order to appreciate the full spectrum of genomic alterations that include aneuploidy, amplifications, deletions, and translocations, especially because these represent some of the most clinically useful genomic alterations in cancer (for example, ERBB2 amplifications). This work has begun, but only in small pilot studies, with larger studies needed to further define these structural alterations in ctDNA $[9,10]$.

Finally, definitive clinical studies that make use of ctDNA are crucial to advance liquid biopsy tests into widespread practice. This will require standardization of a platform of choice, defining the technical variability of this platform, and then performing a properly designed prospective study that addresses a key clinical question involving ctDNA.

Studies like the one by Newman et al. [8] and others [3] continue to bring ctDNA into the spotlight and highlight the various areas in which it shows clinical potential. The next phase of studies will further illuminate the path we need to take to bring ctDNA into the clinic as a meaningful biomarker - one that has the potential to address some of the toughest clinical problems in oncology.

\section{Abbreviations}

CAPP-Seq: Cancer personalized profiling by deep sequencing;

ctDNA: Circulating tumor DNA; NSCLC: Non-small cell lung cancer.

\section{Competing interests}

LAD owns Personal Genome Diagnostics stock, which is subject to certain restrictions under University policy. The terms of these arrangements are managed by the Johns Hopkins University in accordance with its conflict-of-interest policies. The other authors declare that they have no competing interests.

\section{Author details}

'Personal Genome Diagnostics, Baltimore, MD 21224, USA. ${ }^{2}$ Ludwig Center for Cancer Genetics and Therapeutics, Howard Hughes Medical Institute and the Sidney Kimmel Comprehensive Cancer Center at Johns Hopkins, Baltimore, MD 21287, USA. ${ }^{3}$ Swim Across America Laboratory at Johns Hopkins, Baltimore, MD 21287, USA.

Published: 28 May 2014

\section{References}

1. Mandel P, Metais P: [Les acides nucleiques du plasma sanguin chez I'homme]. C R Seances Soc Biol Fil 1948, 142:241-243.

2. Stroun M, Anker P, Maurice P, Lyautey J, Lederrey C, Beljanski M: Neoplastic characteristics of the DNA found in the plasma of cancer patients. Oncology 1989, 46:318-322.

3. Bettegowda C, Sausen M, Leary RJ, Kinde I, Wang Y, Agrawal N, Bartlett BR, Wang H, Luber B, Alani RM, Antonarakis ES, Azad NS, Bardelli A, Brem H, Cameron JL, Lee CC, Fecher LA, Gallia GL, Gibbs P, Le D, Giuntoli RL, Goggins M, Hogarty MD, Holdhoff M, Hong SM, Jiao Y, Juhl HH, Kim JJ, Siravegna G, Laheru DA, et al: Detection of circulating tumor DNA in early- and late-stage human malignancies. Sci Trans/ Med 2014, 6:224ra224.

4. Dawson SJ, Tsui DW, Murtaza M, Biggs H, Rueda OM, Chin SF, Dunning MJ, Gale D, Forshew T, Mahler-Araujo B, Rajan S, Humphray S, Becq J, Halsall D, Wallis M, Bentley D, Caldas C, Rosenfeld N: Analysis of circulating tumor DNA to monitor metastatic breast cancer. N Engl J Med 2013, 368:1199-1209.

5. Diehl F, Schmidt K, Choti MA, Romans K, Goodman S, Li M, Thornton K, Agrawal N, Sokoll L, Szabo SA, Kinzler KW, Vogelstein B, Diaz LA Jr: Circulating mutant DNA to assess tumor dynamics. Nat Med 2008, 14:985-990.

6. Diaz LA Jr, Williams RT, Wu J, Kinde I, Hecht JR, Berlin J, Allen B, Bozic I, Reiter JG, Nowak MA, Kinzler KW, Oliner KS, Vogelstein B: The molecular evolution of acquired resistance to targeted EGFR blockade in colorectal cancers. Nature 2012, 486:537-540.

7. Murtaza M, Dawson SJ, Tsui DW, Gale D, Forshew T, Piskorz AM, Parkinson C, Chin SF, Kingsbury Z, Wong AS, Marass F, Humphray S, Hadfield J, Bentley D, Chin TM, Brenton JD, Caldas C, Rosenfeld N: Non-invasive analysis of acquired resistance to cancer therapy by sequencing of plasma DNA. Nature 2013, 497:108-112

8. Newman AM, Bratman SV, To J, Wynne JF, Eclov NC, Modlin LA, Liu CL, Neal JW, Wakelee HA, Merritt RE, Shrager JB, Loo BW Jr, Alizadeh AA, Diehn M: An ultrasensitive method for quantitating circulating tumor DNA with broad patient coverage. Nat Med 2014, 20:548-554.

9. Diaz LA Jr, Sausen M, Fisher GA, Velculescu VE: Insights into therapeutic resistance from whole-genome analyses of circulating tumor DNA. Oncotarget 2013, 4:1856-1857.

10. Leary RJ, Sausen M, Diaz LA Jr, Velculescu VE: Cancer detection using whole-genome sequencing of cell free DNA. Oncotarget 2013,4:1119-1120.

doi:10.1186/gm552

Cite this article as: Sausen et al:: Circulating tumor DNA moves further into the spotlight. Genome Medicine 2014 6:35. 